\title{
Stage IVA Oropharyngeal (p16-Negative) Carcinoma AJCC v8
}

National Cancer Institute

\section{Source}

National Cancer Institute. Stage IVA Oropharyngeal (p16-Negative) Carcinoma AJCC v8. NCI Thesaurus. Code 133000.

Stage IVA includes: (T4a, N0, M0); (T4a, N1, M0); (T1, N2, M0); (T2, N2, M0); (T3, N2, M0); (T4a, N2, M0). T4a: Moderately advanced local disease. Tumor invades the larynx, extrinsic muscle of tongue, medial pterygoid, hard palate, or mandible. Mucosal extension to lingual surface of epiglottis from primary tumors of the base of the tongue and vallecula does not constitute invasion of the larynx. T1: Tumor $2 \mathrm{~cm}$ or smaller in greatest dimension. T2: T umor larger than $2 \mathrm{~cm}$ but not larger than $4 \mathrm{~cm}$ in greatest dimension. T3: Tumor larger than $4 \mathrm{~cm}$ in greatest dimension or extension to lingual surface of epiglottis. N0: No regional lymph node metastasis. N1: Tumor with metastasis in a single ipsilateral lymph node, $3 \mathrm{~cm}$ or smaller in greatest dimension and ENE(-). N2: T umor with metastasis in a single ipsilateral lymph node, $3 \mathrm{~cm}$ or smaller in greatest dimension and $\mathrm{ENE}(+)$; or larger than $3 \mathrm{~cm}$ but not larger than $6 \mathrm{~cm}$ in greatest dimension and $\operatorname{ENE}(-)$; or metastases in multiple ipsilateral lymph nodes, none larger than $6 \mathrm{~cm}$ in greatest dimension and ENE(-); or metastases in bilateral or contralateral lymph nodes, none larger than $6 \mathrm{~cm}$ in greatest dimension and ENE(-). MO: No distant metastasis. (AJCC 8th ed.) 